\title{
Diffuse reticulum cell sarcoma of the gastrointestinal tract: A problem in diagnosis
}

\author{
K. W. HEATON, J. S. CORNES, AND A. E. READ \\ From the Departments of Medicine and Pathology, The University of Bristol
}

EDITORIAL SYNOPSIS This unusual case extends the differential diagnosis of diffuse intestinal lesions by showing that reticuloses may present in this way.

The reticuloses or malignant lymphomas sometimes involve the gastrointestinal tract. The disease is then usually confined to one portion of the gut, particularly the stomach or the ileum (Allen, Donaldson, Sniffen and Goodale, 1954; Skrimshire, 1955). In the case reported here the lymphoma extended continuously from the stomach to the rectum. The resulting radiological appearances produced great diagnostic difficulty.

\section{CASE REPORT}

The patient, a woman aged 50 years, presented in May 1965 with a two-month history of diarrhoea and lower abdominal pain. She had lost two or three pounds in weight but had a good appetite and did not feel unwell. The only important past illness was pulmonary tuberculosis in 1945 from which she had made a good recovery.

Examination showed a fit-looking, slightly built woman. There was no lymphadenopathy and the heart and lungs were clinically normal. Palpation of the abdomen was difficult but there seemed to be an ill-defined mass on the right side. Rectal examination revealed only third-degree haemorrhoids. Sigmoidoscopy was normal.

INVESTIGATIONS A routine blood count was normal, with $\mathrm{Hb} 14.0 \mathrm{~g} . / 100 \mathrm{ml}$. and W.B.C.s $10,000 /$ c $\mathrm{mm}$. with a normal differential count, but the E.S.R. was raised at $36 \mathrm{~mm}$. in one hour (Westergren). A chest radiograph showed scattered calcified lesions consistent with old healed tuberculous disease. The barium enema was strikingly abnormal (Fig. 1). It showed gross and extensive narrowing of the colon with intervening areas of dilatation. The haustral pattern was lost throughout.

The differential diagnosis at this point seemed to be Crohn's disease of the colon or possibly ulcerative colitis. Ischaemic colitis was also considered. Ulcerative colitis was thought unlikely, especially when a second sigmoidoscopy and a rectal biopsy were both normal. As the disease seemed inactive no special treatment was given except for codeine phosphate to control the diarrhoea.
When the patient was next seen seven weeks later she had obviously deteriorated. The diarrhoea had been relieved but she now had gross ascites, peripheral oedema, generalized muscular wasting, and palpable cervical lymph nodes. A routine blood count, blood urea, and electroly tes were normal, as were liver function tests apart from a serum albumin level of $2.85 \mathrm{~g} . / 100 \mathrm{ml}$. After admission to the ward, paracentesis abdominis was performed and 9 litres of ascitic fluid were withdrawn. It was now possible to palpate several hard nodular masses within the abdomen and a fixed mass in the pelvis. The ascitic fluid, which was straw-coloured, had a protein content of $3.0 \mathrm{~g} . / 100 \mathrm{ml}$. and contained a few inflammatory cells. No malignant cells were seen and the fluid was sterile on culture.

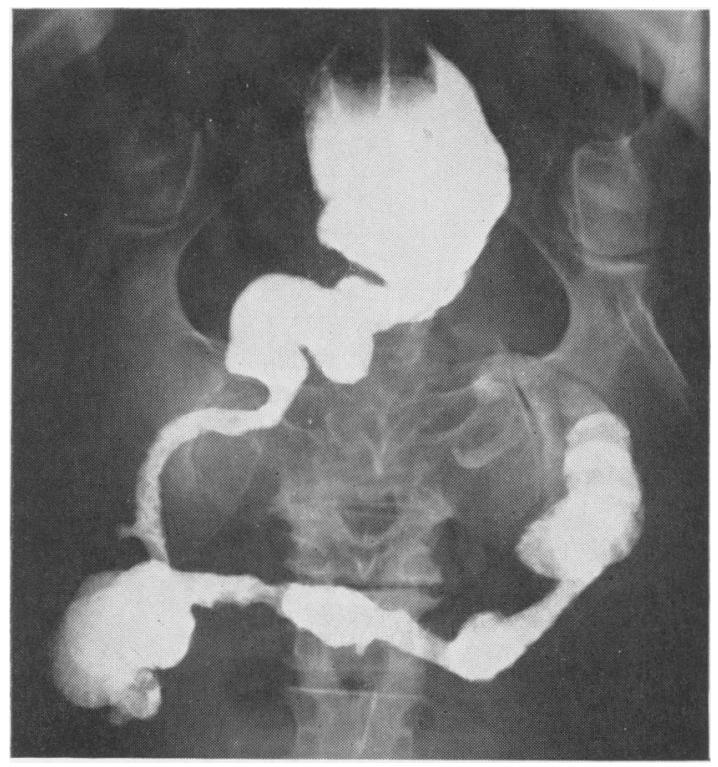

FIG. 1. Barium enema, showing irregular narrowing of the colon with loss of haustration. 


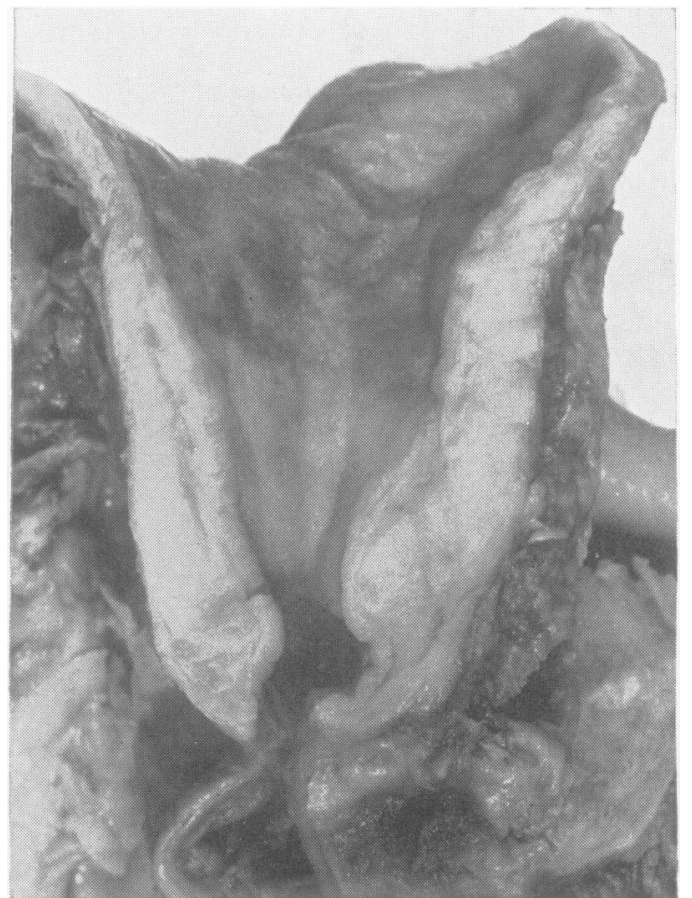

FIG. 2

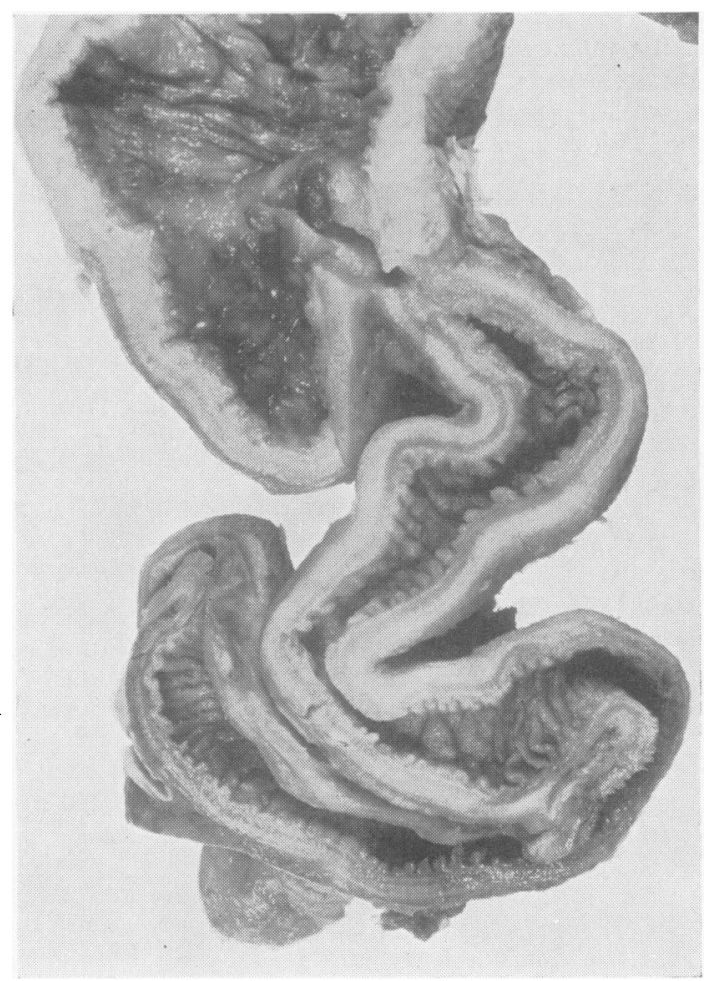

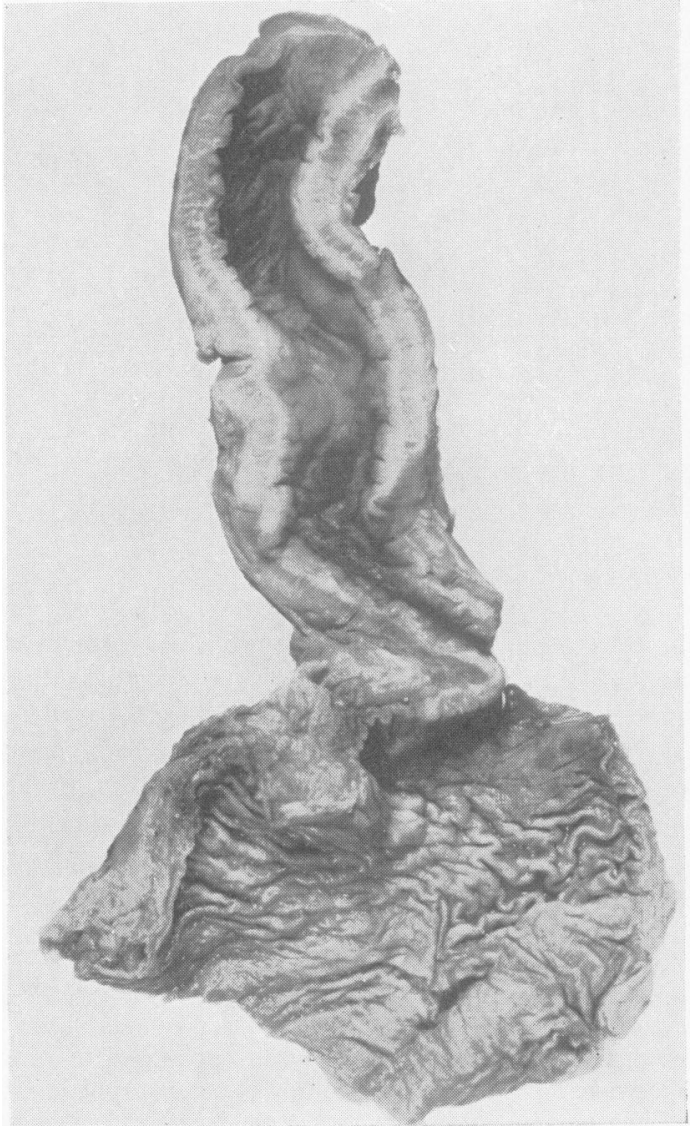

FIG. 4

FIG. 2. Pyloric end of stomach, showing infiltration of the wall by reticulum cell sarcoma.

FIG. 3. Ileo-caecal junction, with tumour involving small and large bowel.

FIG. 4. Recto-sigmoid region, with normal-looking rectum.

FIG. 3 
At laparotomy 10 days later 6 more litres of ascitic fluid were removed. The abdominal contents were covered with fibrinous adhesions and the small intestine was matted together in one mass. Its wall and mesentery were thickened throughout. The colon was indurated and narrowed, while its serosal surface and the peritoneum generally were speckled with white nodules. Peritoneal biopsies were taken and the abdomen was closed.

Post-operatively she developed bronchopneumonia and died 10 days later.

NECROPSY Necropsy seven hours after death confirmed the presence of bronchopneumonia and of healed tuberculous lesions in both lungs. The contents of the peritoneal cavity were stuck together with adhesions and fibrinous exudate. The mesenteric, retroperitoneal, and mediastinal lymph nodes were enlarged and replaced by white tumour tissue. The most impressive findings were in the gastrointestinal tract, with gross changes in the stomach, ileum, and colon (Figs. 2, 3 and 4). The body and the pyloric end of the stomach were narrowed and their wall was greatly thickened, in places up to $0.8 \mathrm{~cm}$., while the mucosal surface was granular. The duodenum, jejunum, and proximal ileum appeared normal. In the middle and distal ileum there was again gross thickening of the wall with a finely granular mucosal surface. No ulceration was seen. In the terminal ileum the solitary lymphoid nodules and Peyer's patches were enlarged. The entire colon from caecum to rectosigmoid junction was affected. Its wall was uniformly thickened and the mucosal surface was granular throughout (as in healing ulcerative colitis), while the lumen was moderately narrowed in some areas and slightly dilated in others. The disease seemed to stop abruptly at the rectosigmoid junction, the rectum having a normal appearance apart from some mucosal congestion.

HISTOLOGY Reticulum cell sarcoma was found in sections from all parts of the gastrointestinal tract, from lymph nodes in the mesentery, para-aortic region, mediastinum and neck, and in sections of bone marrow from lumbar and thoracic vertebrae. The liver and spleen were not involved. The tumour was composed of large cells with big, slightly indented vesicular nuclei, prominent nucleoli and moderate amounts of weakly eosinophilic cytoplasm (Fig. 5a). A few multinucleate giant cells were seen, and one to three mitotic figures were present in each highpower field. Sections impregnated with silver salts showed abundant reticulin in all areas (Fig. 5b). The possibility of an anaplastic carcinoma was considered but stains for mucin were negative and examination of many sections failed to reveal any trace of a glandular pattern.

Sections from the gastrointestinal tract showed tumour cells in all layers of the gut wall, maximally in the submucosa and subserosa. Although the duodenum, jejunum, and rectum had looked normal to the naked eye, all were found on microscopy to be infiltrated by tumour cells. Histology therefore revealed that the sarcoma extended continuously from the stomach to the rectum.

\section{DISCUSSION}

Pathologically this case is of interest because the

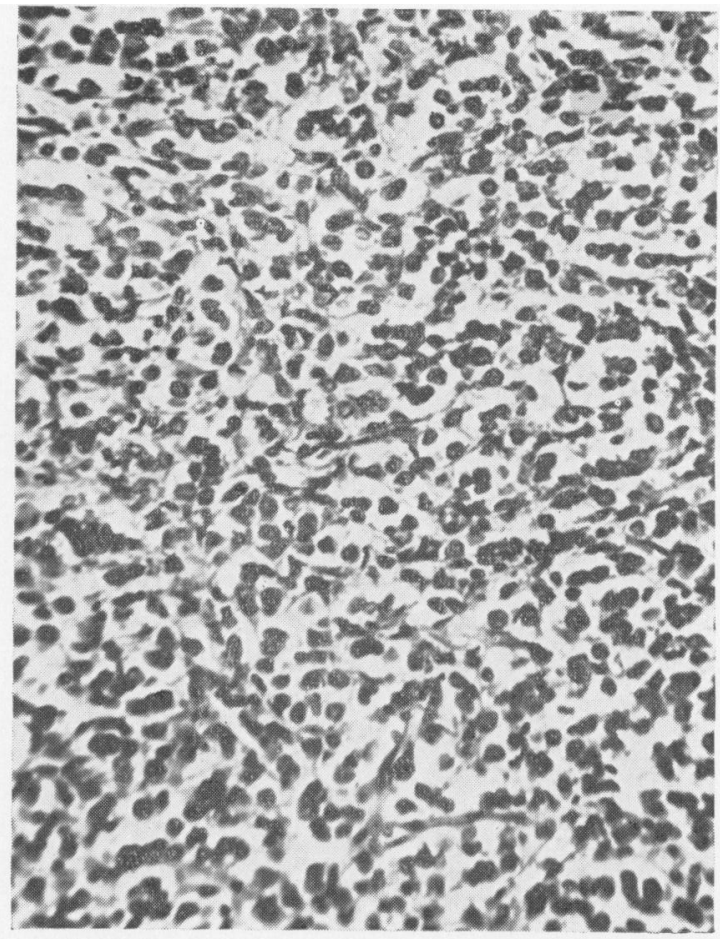

FIG. 5a

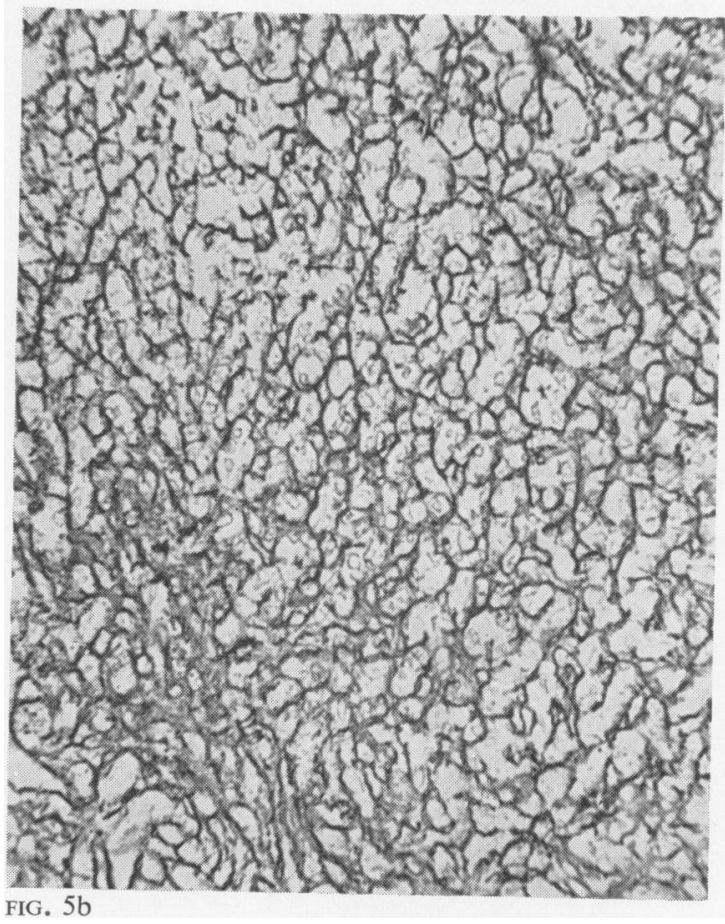

FIG. 5. Jejunum, section of tumour in submucosa; (a) haematoxylin and eosin $\times 200$. (b) reticulin impregnation $\times 200$. 
involvement of the gastrointestinal tract by reticulum cell sarcoma was unusually extensive. It is well known that the stomach and intestines may be affected by the reticuloses or malignant lymphomas, and a number of relevant reviews have appeared in the American literature (Usher and Dixon, 1943; McSwain and Beal, 1944; Marcuse and Stout, 1950; Faulkner and Dockerty, 1952; Allen et al., 1954; Darling and Welch, 1959). There have been few comparable papers in British journals (Skrimshire, 1955; Azzopardi and Menzies, 1960; Dawson, Cornes, and Morson, 1961). These papers record lesions of reticulum cell sarcoma, lymphosarcoma, and Hodgkin's disease, occurring in all parts of the gastrointestinal tract from the stomach to the rectum. In practically every case reported it is clear that the lesions were distinct and localized, though occasionally multiple. Diffuse infiltration to the extent that occurred in this patient has not previously been documented. Eight of the nine reviews mentioned above, covering 292 cases of gastrointestinal reticulosis, do not between them record a single case of diffuse infiltration. One review (Marcuse and Stout, 1950) records four cases of diffuse infiltration. In two patients the disease was limited to the duodenum or jejunum and in the other two patients, both with reticulum cell sarcoma, the infiltration involved part of the colon as well as the ileum. Infiltration of the small intestine alone is described by Eakins, Fulton, and Hadden (1964), but extensive thickening of the bowel wall does not seem to have been a feature of their cases.

A different type of widespread gastrointestinal involvement is found in multiple lymphomatous polyposis (Cornes, 1961). In this condition pedunculated or sessile polyps may be present in great numbers throughout the entire gastrointestinal tract. In these lesions, however, the lymphomatous tissue is limited to the mucosa and submucosa, whereas in the present case the full thickness of the bowel wall was infiltrated.

The macroscopic appearances in this case were indistinguishable from those of linitis plastica with diffuse intestinal involvement (Fernet, Azar, and Stout, 1965). In this condition the tumours are all mucin-secreting adenocarcinomas and a glandular pattern may be found in some areas if enough sections are examined. In the present case there was no evidence of mucin production, nor was there any trace of acinar pattern in the numerous sections examined. Moreover, sections from several lymph nodes showed loss of normal structure with complete replacement of lymphoid tissue by reticulum cell sarcoma. Tumour deposits were not found in peripheral sinuses, invading and partially destroying the lymph nodes, as they are in carcinoma.
The clinical and radiological interest of this case lies in the very unusual appearances at the barium enema examination. The commonest cause of such a picture of alternating stenosis and dilatation would probably be Crohn's disease of the colon (Wolf and Marshak, 1962; Lockhart-Mummery and Morson, 1964). Other differential diagnoses that may be considered are ischaemic colitis and chronic amoebic dysentery. In ischaemic colitis, however, there is usually a single stricture in the region of the splenic flexure (Marston, Phiels, Lea Thomas, and Morson, 1966). Multiple strictures may be found in chronic amoebic dysentery (Middlemiss, 1961) and may indicate the presence of multiple amoebomata in the wall of the colon (Lumsden and Truelove, 1965). Ulcerative colitis seldom causes such discontinuous narrowing of the colon.

The radiological appearances of reticuloses of the colon are usually said to be similar to those of carcinoma or to be aneurysmal in outline (Lumsden and Truelove, 1965). It now appears that colonic involvement by reticulosis can lead to areas of narrowing and loss of haustral pattern on barium enema examination, and it is suggested that this diagnosis be considered whenever such a picture is seen.

SUMMARY

A 50-year-old woman presented with diarrhoea and after a short illness the gastrointestinal tract was found to be extensively invaded by reticulum cell sarcoma. The stomach and the whole of the small and large bowel were infiltrated to an extent not previously documented. The radiological appearances on barium enema examination were misleadingly suggestive of Crohn's disease of the colon.

\section{REFERENCES}

Allen, A. W., Donaldson, G., Sniffen, R. C., and Goodale, F., Jr. (1954). Primary malignant lymphoma of the gastro-intestinal tract. Ann. Surg., 140, 428-438.

Azzopardi, J. G., and Menzies, T. (1960). Primary malignant lymphoma of the alimentary tract. Brit. J. Surg., 47, 358-366.

Cornes, J. S. (1961). Multiple lymphomatous polyposis of the gastrointestinal tract. Cancer (Philad.), 14, 249-257.

Darling, R. C., and Welch, C. E. (1959). Tumors of the small intestine New Engl. J. Med., 260, 397-408.

Dawson, I. M. P., Cornes, J. S., and Morson, B. C. (1961). Primary malignant lymphoid tumours of the intestinal tract. Brit. J. Surg., 49, 80-89.

Eakins, D., Fulton, T., and Hadden, D. R. (1964). Reticulum cell sarcoma of the small bowel and steatorrhoea. Gut, 5, 315-323.

Faulkner, J. W., and Dockerty, M. B. (1952). Lymphosarcoma of the small intestine. Surg. Gynec. Obstet. 95, 76-84.

Fernet, P., Azar, H. A., and Stout, A. P. (1965). Intramural (tubal) spread of linitis plastica along the alimentary tract. Gastroenterology, 48, 419-424.

Lockhart-Mummery, H. E., and Morson, B. C. (1964). Crohn's disease of the large intestine. Gut, 5, 493-509. 
Lumsden, K., and Truelove, S. C. (1965) Radiology of the Digestive System. Blackwell, Oxford.

McSwain, B., and Beal, J. M. (1944). Lymphosarcoma of the gastrointestinal tract. Ann. Surg., 119, 108-123.

Marcuse, P. M., and Stout, A. P. (1950). Primary lymphosarcoma of the small intestine. Cancer (Philad.), 3, 459-474.

Marston, J. A. P., Phiels, M. T., Lea Thomas, M., and Morson, B. C. (1966). Ischaemic colitis. Gut, 7, 1-15.
Middlemiss, H. (1961). Tropical Radiology. Heinemann, London. Skrimshire, J. F. P. (1955). Lymphoma of the stomach and intestine. Quart.J. Med., 24, 203-214.

Usher, F. C., and Dixon, C. F. (1943). Lymphosarcoma of the intestines. Gastroenterology, 1, 160-178.

Wolf, B. S., and Marshak, R. H. (1962). Granulomatous colitis (Crohn's disease of the colon): roentgen features. Amer. $J$. Roentgenol., 88, 662-670. 